\title{
Use of social media by self-help and mutual aid groups
}

\section{Melanie Boyce ${ }^{1}$, Patience Seebohm², Sarah Chaudhary ${ }^{3}$, Carol Munn-Giddings ${ }^{4}$, and Mark Avis ${ }^{5}$}

\begin{abstract}
This paper explores the use of social media by self-help/mutual aid groups that meet on a regular face-to-face basis. It draws on data from the ESTEEM project, which ran from 2010 to 2013 with the overall aim of developing a range of resources for health and social care practitioners on how to support self-help/mutual aid groups. A re-examination of the interviews and discussions that were undertaken with 21 groups in two UK sites indicated that groups' use of social media was becoming an increasingly important resource. The findings highlight a range of benefits and limitations with selfhelp/mutual aid groups using social media and suggest a blurring of boundaries between online and face-to-face groups. For groupworkers involved with self-help/mutual aid groups opportunities in developing groups' online presence are raised.
\end{abstract}

Keywords: self-help groups; mutual aid groups; social media; peer support; online groups; groupwork; group work

1. Research Fellow, Anglia Ruskin University

2. Independent Researcher

3. Research Assistant, Nottingham University

4. Professor in Participative Inquiry, Anglia Ruskin University

5. Professor of Social Contexts of Health, Nottingham University

Address for correspondence: Melanie.Boyce@anglia.ac.uk

Date of first (online) publication: November 25th, 2014 


\section{Background}

\section{Self-help/mutual aid groups}

Defining any group is problematic, as groups can be defined in many different and often competing ways (Madden, 2011). Diversity in form, function and focus in self-help/mutual aid groups have contributed to a range of different definitions. Despite this a number of key characteristics are largely agreed on, which relate to people who share a similar experience or shared condition, coming together for mutual support in a group that is managed and owned by its voluntary membership (Wilson, 1994; Elsdon et al, 2000).

The term self-help is somewhat misleading, as it implies that people are involved in the group as a means of only helping themselves (King \& Moreggi, 2006). Instead, as Munn-Giddings and Borkman (2005, p.140) highlight, it is a combination of self-interest with the mutuality of relationship with others, and the consequent processes within the group, that 'helps the individuals to help themselves'. In addition to the groups' supporting role, groups often engage in other activities, such as information sharing and awareness raising (Adamsen $\&$ Rasmussen, 2001; Gray et al, 1997).

Brown (1994) identifies 'self-help, mutual support models' as one of eight mainstream models of social groupwork and draws attention to the potential tensions that can develop between these groups and practitioners. The experiential knowledge base and focus on mutual support are the main features that distinguish self-help/mutual aid groups from professionally led support groups (Munn-Giddings \& McVicar, 2006). For these reasons some practitioners have expressed reservations and concerns about self-help/mutual aid groups, which appear to be in conflict with professional ideals (Douglas, 1993; Wilson, 1994).

In recent years this dichotomous view has been brought into question and instead it is argued that practitioners' involvement in selfhelp/mutual aid groups is far more common than previously thought (Adamsen $\&$ Rasmussen, 2001). Practitioners are frequently involved in initiating these groups, by bringing members together, along with facilitating and organising groups at certain points during their life course (Aglen et al, 2011). Although some self-help/mutual aid groups 
may reject any professional input on the basis of knowledge base, the vast majority are likely to have negotiated varying levels of involvement and support from practitioners (Shepherd et al, 1999; ESTEEM, 2013).

Potential benefits for members of a self-help/mutual aid group are increasingly recognised as wide-ranging, with improvements in wellbeing and health outcomes (Pistrang et al, 2008; Seebohm et al, 2013), along with personal gain, such as increased self-esteem, improved relationships and decreased levels of isolation (Gray et al, 1997). Gaining exact figures on the numbers of operating self-help/mutual aid groups in the UK remains problematic, yet it is largely agreed that the number has dramatically risen over recent decades (Elsdon et al, 2000; Chaudhary et al, 2010).

Similarly there has been an unparalleled expansion in the growth of online self-help/mutual aid groups. Accurate records remain problematic, but they are estimated to number hundreds of thousands worldwide, covering a diverse range of conditions and experiences (King \& Moreggi, 2006). The value and limitations of such groups have been widely debated, but it is largely agreed they are similar in philosophy and approach to face-to-face self-help/mutual aid groups, but are not restricted by the constraints of time and distance (Finn, 1999). By using interactive forums like social media, online self-help/mutual aid groups have successfully utilised new technologies to provide support to their members (Levine, 2005).

\section{Social media}

The terms social media and social networking are frequently used interchangeably, and although they are not mutually exclusive, Murthy (2012) states, distinct differences exist between them. A social network site enables users to form a 'public profile within a bounded system', whereby they can view and engage with other users to whom they share a direct and indirect connection (Boyd \& Ellison, 2008). In comparison social media, Murthy (2012, p.106) argues, relates to

[a] medium wherein 'ordinary' people in ordinary social networks (as opposed to professional journalists) can create user-generated 'news' (in a broadly defined sense. 
However, Correa et al (2009) suggest that our understanding of the term social media has moved on from its traditional informational media origins and instead now encapsulates users connecting, communicating and interacting with each other through the Internet and digital media. Various online and mobile electronic tools enable these connections to be made, which include e-mail, texting, microblogging (for example, Twitter), and smartphone applications (Fisher, 2012).

Increasingly the use of social media is being promoted as an area for development in healthcare delivery. Social network sites, like Facebook, have been identified as a unique and effective way for people to develop and maintain relationships. It is this social connectedness, Grieve et al (2013) suggest, which has the potential to improve psychological wellbeing. Possible improvements in mental health outcomes and the potential to strengthen communication between professionals and service users through a low cost medium, means social media is increasingly being identified as an area for development in healthcare delivery (Greive et al, 2013; Seil, 2012).

Similarly, growing research in online self-help/mutual aid groups indicates many of the features valued by members attending face-toface groups, such as mutual support, information sharing (Finn, 1999) and access to others with similar concerns (King \& Moreggi, 2006), are found within online groups. Yet fundamentally participation in online self-help/mutual aid groups remains restricted to those with access to a computer and who have the ability to type, either directly or indirectly through access to assisted technologies. Therefore, King and Moreggi (2006) conclude, participation in an online self-help/mutual aid group may be far more restricted than often previously assumed.

\section{Digital divisions}

Inequalities in access to online self-help/mutual aid groups are indicative of the wider divisions that have emerged in the use and access to information and communication technologies (ICT). Since the 1990s there has been a growing concern about the emerging 'digital divide' between groups of users. Digital exclusion first emerged in relation to the technological disparity between developed and developing nations, but has since come to also represent the inequalities within individual countries (Selwyn, 2004). Stratified inequalities that focused on patterns 
of use/non-use were identified, and age was commonly determined as the main factor determining engagement with internet technologies (Sourbati, 2009).

In recent years, a more complex and nuanced pictured has emerged in relation to access and use of ICT. Having been largely overlooked until very recently disability is increasingly recognised as an excluding factor in the use and access of ICTs (Sourbati, 2012). Cost and technical accessibility barriers, rather than the person's impairment, are largely identified as the main reasons, as adaptive technology often lags in development behind the technology to which it is supposed to enable access and remains expensive and difficult to learn (Dobransky $\&$ Hargittai, 2006). Yet disability status with ICT use is not universal. Similarly not all disabled people are equally disadvantaged. Instead, disabled peoples' use of ICT is entwined with a host of complex factors, which Dobransky and Hargittai (2006) argue requires careful examination when examining ICT use by disabled people.

However, as the UK government plans to make public services 'digital by default' (Helsper, 2011), along with a growing interest in utilising social media in healthcare delivery, those who are unable or choose not to engage with digital ICTs will have a potentially lower level of choice and a reduced range of benefits available to them (Sourbati, 2012).

\section{Methodology}

\section{Context and setting of study}

In 2010 the Big Lottery funded the ESTEEM project, a collaboration between Anglia Ruskin University, Nottingham University and Self Help Nottingham (a specialist charity that supports self-help/mutual aid groups), to develop a range of resources for health and social care practitioners on how best to support self-help/mutual aid groups. The research is now complete and this paper draws on the Stage 1 data that was gathered from 2010 to 2011 and follow-up communication in 2013. The research was carried out in Essex and Nottingham and ethical approval was given by the respective Research Ethics Committees at both universities. 


\section{Research design and methods}

ESTEEM applied a staged, participatory approach in relation to its research design, which meant self-help/mutual aid group members, practitioners, commissioners and academics came together to plan and review the research and development of the resources throughout the project's three stages.

The four characteristics that are largely agreed as features indicative of self-help/mutual aid groups were taken as the group's inclusion criteria:

- Members share an experience or problem.

- Members come together for mutual support.

- Members control and own the group.

- Membership is voluntary.

(Wilson, 1994; Elsdon et al, 2000).

Self Help Nottingham holds and manages a local database of selfhelp/mutual aid groups that meet face-to-face, which provided us with a sampling frame of 202 suitable groups in this area. In Essex, as perhaps more comparable to the rest of the country, we had to draw on a range of sources to identify a sampling frame. Therefore websites, professional contacts and localised search engines led to the identification of 24 groups. At each site 10 groups were purposively selected to include:

- A range of health and social issues.

- Established and new groups (not more than two years old).

- Affiliated and independent groups.

- Groups run by and for people from Black, Asian and minority ethnic (BAME) communities.

All selected groups agreed to participate except one as group members did not feel outsider support and involvement were relevant to the group. However the group coordinator agreed to be interviewed and a further group was successfully recruited. In total there was a sample of 21 groups, with limited data from one group. To guarantee anonymity groups are numbered in the Findings without reference to site or focus.

During June 2010 to February 2011 the Stage 1 data was collected. In total 21 semi-structured interviews were undertaken with group 
coordinators, lasting between 45-120 minutes, along with 20 group discussions with group members of 45-90 minutes. All interviews and discussions were recorded and fully transcribed, except in five occasions when groups preferred written notes to be taken. The interviews and discussions focused around the groups' ethos, activities, achievements, challenges, links and networks.

Entering into the final stage of the project involved, amongst other activities, a re-examination of the data. In doing so groups' use and nonuse of social media was identified as an area for further examination by the research team. The first author re-examined the 41 transcripts thematically following the six phases as outlined by Braun and Clark (2006) using the software programme Nvivo to aid the organisation and retrieval of the data. An additional final phase involved further discussions, through email, with three groups to clarify their reasons and progress in the use of these new technologies. Written consent was obtained from group members for the use of this correspondence.

\section{Findings}

The findings begin by describing the participating groups and are then presented under the following two headings: Benefits of social media use; Limitations and barriers of social media use for self-help/mutual aid groups, with sub-heading under each of these.

\section{Overview of groups}

The twenty-one participating groups focused on a wide range of issues. This comprised physical health conditions $(n=10)$, mental health $(n=5)$ and socially isolating situations $(n=6)$, such as family carers. However, this categorisation was not clear-cut as the majority of health focused groups actively sought to reduce members' isolation. Similarly health issues were frequent topics of conversation for members from socially isolated groups.

Similar variety was also seen in the size, venue, frequency and style of group meetings. For instance, some groups had over 30 regularly attending group members, whereas other groups were half this size. Some groups met weekly, whereas others were meeting monthly 
or bi-monthly. Meetings were being held in cafes, hospitals and community-based premises. Informality characterised the style of most meetings, although some groups favoured more formal arrangements. In nearly half the groups a paid practitioner had taken a lead role in initiating the group and 8 groups were affiliated to national charities.

There was one group from Essex and six groups from the Nottingham area where no references to social media were made in either the coordinators' interviews or group discussions, mainly as they were not engaging in nor had plans to make use of these interactive tools. Three of these groups' main focus was physical ill-health, two were mental health issues and the remaining two were socially isolating issues.

The reasons as to why the use of social media was less common in Nottingham than Essex are somewhat speculative, as data was not collected on this. A possible explanation is that as these groups were in Self Help Nottingham's online directory (which is also widely distributed in paper format across the county to a range of health and social care practitioners), the task of promotion was perhaps less pressing than it was for the groups in Essex, where there was no equivalent supporting organisation like Self Help Nottingham. Therefore the findings presented below are drawn from members' responses from 14 groups and Table 1 shows the focus of issues across these groups.

Table 1

The focus of participating groups $n=14$

\begin{tabular}{|l|l|l|}
\hline $\begin{array}{l}\text { Physical health } \\
(n=7)\end{array}$ & $\begin{array}{l}\text { Mental health } \\
(n=3)\end{array}$ & $\begin{array}{l}\text { Social isolation } \\
(n=4)\end{array}$ \\
\hline $\begin{array}{l}\text { Aphasia (1) } \\
\text { Cancer (2) } \\
\text { Diabetes (1) } \\
\begin{array}{l}\text { Drugs \& Alcohol (1) } \\
\text { Myalgic Encephalomyelitis } \\
\text { (ME) (1) }\end{array}\end{array}$ & $\begin{array}{l}\text { Diagnosis specific (2) } \\
\text { General (1) }\end{array}$ & $\begin{array}{l}\text { Chinese people (1) } \\
\text { Gay men (1) } \\
\text { Vertigo (1) }\end{array}$ \\
$\begin{array}{l}\text { Parents group (1) (for } \\
\text { children with autism) } \\
\text { South Asian women (1) }\end{array}$ \\
\hline
\end{tabular}




\section{Benefits of social media use for self-help and mutual aid groups}

\section{Group benefits}

Attracting new members and widening membership

A common concern for many groups was around membership numbers. Group members spoke about the ideal member numbers they were seeking for their groups, which was often linked to the maximum size of their meeting venue:

Parl: We'd like 5 more members.

Par2: Yes 5 or 6 more members, yes, but not 30 or 40. (Group 13)

It's nice to have new blood... we'd be happy with 15 or 16 members, the room's not big enough to take any more, but it would be nice to expand that little bit more. (Group 9)

I'm disappointed that the numbers are small, but in actual fact it's probably been an asset in the sense that we've got to know each other really well... The contact list is 15 now... the place only holds 30, so if we had more than 30 we'd have to move, but I would like the place full. 25 to 30 each meeting. (Group 11)

There were seven groups that managed their own group website and all had an email publicised on their websites for people to use as a means of contacting the group. Group members frequently said how they found this an invaluable tool in attracting new members to the group at a local level and sometimes at national and international level:

We got a website up and going, we got onto the search engines so automatically people would put in [locality and group focus] or something, and up our group would come, and that created a link for people to email us and then we could contact them via email. (Group 21)

We've got emails and we're forever getting emails from new people around the world... we've got members in the outer Hebrides, Hawaii, Australia, America all 
over. We get people emailing us 'What's wrong with me?' 'Can you tell me what to do?' (Group 4)

Similarly, of the four groups that had developed a Group Facebook Page, one key member said they found this a useful tool for attracting new members, particularly for those who might not be accessing services:

The Facebook Group and Page are amazingly good... way to attract new members and or welcome them to the group... It is a way of reaching new members who perhaps do not access secondary services where most of our posters and leaflets are placed. (Group 11)

\section{Keeping members informed and updated}

Most groups met on a monthly or bi-monthly basis; as a result social media was mostly being used as a way of updating the current membership. This might be through the key member using the group Facebook page to 'send invites out to members for meetings and social activities' (Group 11) or using it as a portal for group members 'to access information' (Group 14).

Social media was also being used as a way of quickly gathering group members' views, particularly in relation to contributing to service consultations and participating in patient and public involvement processes. Akin to the member-led ethos of self-help/mutual aid groups, one group member said how they used email as a way of gathering member views at short notice:

Often there is always this window that you have an opportunity and because you can communicate by email it's often saying, 'This has come about, we need to do something', I need to hear, this is my view, what are other people's views, what do we do with it? (Group 12)

Additionally, text messages were frequently being used between members, as a way of staying in touch with one another and to provide more personalised support:

Or even just send somebody a text message is, you know, it makes them feel a little bit better. (Group 17) 


\section{Keeping costs down}

On the whole most groups received funds through their membership fees or fund-raising activities. Even for those groups who had been awarded small amounts of funding it was often a struggle to meet the running costs of the group. The biggest expense was the hiring of premises for group meetings, but postage costs were a common additional expenditure. Consequently group members spoke about the cost benefits associated through making use of email and a Group's Facebook page as a means of keeping costs down:

Emails are free, aren't they? (Group 15)

We've got kind of an idea with the communication thing that postage is a big issue, we've just recently discussed this, to try and get people's email address, or if they haven't got an email address, if their sons or daughters or grandchildren have got email addresses where we could send stuff to, because it's obviously going to save us a lot of money and probably time stuffing bits in envelopes and stuff like that and also you've got to think the electronic age is obviously a better way of communicating, it's bigger and quicker. (Group 18)

It is a way for members to message me [via Facebook] without having to pay for it. (Group 11)

\section{Individual benefits}

\section{Feeling supported and connected}

The face-to-face group meetings were not the only way members were receiving support, as many members spoke about the support they received outside the meetings through regular text and email correspondence with each other:

It's not a here all and end all, you know. We talk to each other, we communicate on the internet...texting, yeah, so you know, it's not the formal thing where that is that. (Group 12)

We email each other and we text each other and phone and see each other, so we've always got that constant support there. (Group 6) 
For those groups with Facebook pages this interactive networking tool meant group members had another forum to share experiences and provide mutual support in a safe, confidential space:

It is a closed Group Forum where members can share their experiences safely and confidentially... [and] receive peer support. (Group 11)

We've got [name of group] on Facebook as well and you know if parents have got any issues they can get on and they might get 4 or 5 other parents that reply to them so you're never quite on your own. (Group 6)

\section{Meeting different needs}

Of the four groups that had developed Facebook group pages, two members spoke of how they were now connecting with new members who were not attending the face-to-face meetings. For one group this was because the group was not local to the new members, whereas for another member it seems that face-to-face support was not what they were looking for:

We have Facebook members who have never been to one of our meetings, in fact some do not live anywhere near [locality] but this is their only form of peer support. (Group 11)

I had one [organisation] call who said they had this parent who would really benefit from being in your group, would you mind giving her a ring? They had asked her and she said that was ok. So I did that and she, for maybe the last quarter of the year, has known about us, but still hasn't accessed the group.... she's on our Facebook group so our secretary will send her a text you know 'Hi how are you today?' that type of thing. So I'm hoping she's going to start to come along to the coffee morning. (Group 6)

Being able to offer group members support and interaction through a mixture of face-to-face and online tools was identified by some group members as a valuable way of meeting members' varied needs and preferences:

I think of course a lot of people get a different sort of help using the internet... and different people need different things. Some people need face-to-face... and 
I think you need all the different ones. So different people need different ways of getting information and support. (Group 5)

I think there's a difference between, we'd like to reach more people and you can reach more people, not just face-to-face, you can do it on the phone, you can do it by email, so I think we would like to be able to reach more people... So it's having that flexibility and being able to meet different needs. (Group 12)

\section{Limitations and barriers of social media use for self-help/mutual aid groups}

\section{Hesitancy and resistance}

A small number of group members spoke about their members' resistance, along with their own hesitancy, in engaging with digital resources:

A lot of our members are, they don't connect with the internet age and I don't see why they should have to. (Group 18)

I haven't got any inclination to want to learn how to use a computer. (Group 14)

Some group members said they felt age was a barrier to their members engaging with new technologies, although engagement was often found to vary within groups:

I think people of a generation tend not to talk on the internet, it's a young thing. (Group 16)

The ones that can read and write into English are retired and they don't use computers. (Group 10)

Yes, the treasurer has an e-mail and the chairman has an e-mail and one member has an e-mail, but nobody (else) has an email... they didn't use a computer before, so it's too late they think, it's too late to have a computer now. (Group 13)

\section{Additional work}

Whilst initial hesitancy to engage with new technologies was expressed by members of one group, a group Facebook page has recently been 
developed. Along with the benefits identified earlier, the key member spoke about the additional work this resource had meant for him:

... harder on me having now a lot more than just phone calls to catch up on. (Group 14)

Additional work developing and maintaining an online group presence was an area group members said they were struggling with, which was hampered by the voluntary nature of group member involvement:

We've been struggling even to put the website on or email address or something like that. (Group 19).

Too much like hard work for someone to update it [website] we've got no employees, we're all volunteers. We thought about it, someone said they'd do us a website, but we are on one or two other websites. (Group 4)

\section{Not for everyone}

Just as face-to-face self-help/mutual aid groups are not necessarily for everyone, neither is engaging with online interactive resources. For instance, members from the ME group spoke about how sitting at a computer for any period of time can be detrimental to their physical health:

Par 1: And some people actually with ME say that actually computer access is a problem because it requires your constant attention looking at screens and pressing buttons and that's using up valuable energy.

Par 2: I find, yes, I go to sleep sat at the computer quite often. (Group 16)

Another group had found that as established and potentially new members do not all have access to the internet, a recently developed group Facebook page was hardly being used:

We did create a Facebook page, however have found that it has not been that successful. Many of our members and probably potential members don't have access to the internet. We will keep it on our radar as things change all the time. (Group 18) 


\section{Discussion}

As the use of social media by self-help/mutual aid groups was not the focus of the main study, group members were not explicitly asked about their use of it. If direct questions about social media use had been asked it is likely the thoughts and views indirectly gathered would have been more detailed. Despite these limitations the findings provide insights into the growing use of social media by self-help/mutual aid groups that meet face-to-face.

On the whole the literature has tended to distinguish between selfhelp/mutual aid groups that meet face-to-face and those that are online (Finn, 1999; Madara, 1997; King \& Moreggi, 2006). However, as most of the groups that participated in this study had or were developing an online group presence our findings suggest these divisions are somewhat artificial, as the boundaries are becoming increasingly blurred.

The recognised benefits associated with new technologies, such as its inherent low-costs, accessibility, speed and convenience (Simon $\&$ Stauber, 2011), were positive features group members were able to apply in ways that were meaningful and beneficial for their groups. Having an online presence meant some groups were becoming more accessible, as many were attracting a much wider membership. These online members were more geographically dispersed and unlike those members meeting face-to-face were not always in receipt of services. In some cases these new members were entering into the face-to-face meetings, whilst others chose to remain an online member.

On the whole a core, local membership typifies self-help/mutual aid groups that meet face-to-face (Borkman, 1999), yet our findings highlight the different layers of group membership as being much more varied and fluid. It was beyond the scope of this study to explore the impact of this widening membership, yet potentially it is likely to broaden and enrich the group's knowledge base. As a number of the groups were being asked to contribute to service consultations and were involved in public and patient involvement processes a wider knowledge base is advantageous. The use of social media made it possible to respond to short notice requests.

Similarly, engaging with social media for some groups brought with it a number of practical benefits. The running costs of the group were being reduced and it provided an efficient way of informing and 
updating members on a range of issues and developments. In addition to the practical benefits, social media was providing some group members with an additional layer of connection and peer support, as many members were using Facebook, email and text, to remain in contact with each other outside group meetings. This meant support and contact was potentially available any time, unlike the face-to-face group meetings that were restricted to a particular time and place.

Despite the wide and varied benefits associated with self-help/ mutual aid groups engaging with new technologies like social media, it also raises a number of distinct challenges. A member-led ethos is synonymous with self-help/mutual aid groups, but often one or two key members are responsible for the running of group, which at times can become onerous and burdensome (Wituk et al, 2002). The account of one key member highlights that developing and maintaining an online group presence potentially adds to these burdens of responsibilities. The voluntary, self-governing principles of self-help/mutual aid groups mean members can only do so much, which can be hampered by the preceding condition or members' skills and available expertise in a group.

Conversely the potential benefits associated through engaging with social media, in relation to access and accessibility, also raise a number of concerns. Developing an online group presence may widen group member inclusion, yet it also raises questions around who is potentially being excluded in these initiatives. The ease and efficiency of social media makes it an attractive resource to apply in the running of the group and in its provision of peer support. Yet for those members who are not online there is the potential for these members to feel excluded from the dialogue that takes place online and inevitably the wider group in general. Also as new technologies are increasingly being used as a way of being involved in public and patient involvement processes, for those group members who are not online their voices are potentially not being heard. Additionally, online communication between group members raises concerns about the increased possibility for negative or hostile encounters that can occur online if inadequate checks and controls are in place (Finn, 1999).

Clearly not all groups and their members want to engage with new technologies, as a third of the project groups were not engaging or looking to develop their activities in this area. Likewise for those groups that were developing and using social media engagement varied 
between members, with unfamiliarity and unease expressed as a barrier to engagement. For groupworkers involved with self-help/mutual aid groups it provides, as Simon and Stauber (2011, p.14) identify, an opportunity to 'revitalize groupwork's role in today's environment', through promoting the value of social media for such groups and supporting those who wish to develop an online group presence.

\section{Conclusion}

The conclusions that can be drawn from the re-examination of the data can only be viewed as emergent, as the use of social media was not the focus of the study. Nonetheless from the data available the findings indicate that social media is increasingly becoming an important resource for self-help/mutual aid groups that meet face-to-face. It also highlights how group members are choosing to engage and apply social media in ways that suit themselves and their groups. Through doing so it would suggest the boundaries between online and face-to-face self-help/ mutual aid groups are becoming increasingly blurred. Further research is needed to explore the impact on such groups and its members as a result of these potential blurring boundaries, along with the possible opportunities for groupworkers.

\section{References}

Adamsen, L. and Rasmussen, M. (2001) Sociological Perspectives on Self Help Groups: Reflections on Conceptualisation and Social Processes. Journal of Advanced Nursing, 35, 6, 909-917

Aglen, B., Hedlund, M. and Landstad, B.J. (2011) Self-help and self-help groups for people with long-lasting health problems or mental health difficulties in a Nordic context: A review. Scandinavian Journal of Public Health, 39, 813-822

Borkman, T. (1999) Understanding Self Help / Mutual Aid: Experiential Learning in the Commons. New Jersey: Rutgers

Braun, V. and Clarke, V. (2006) Using thematic analysis in psychology. Qualitative Research in Psychology, 3, 77-101

Boyd, D.M. and Ellison, N.B. (2008) Social network sites: definition, history, and scholarship. Journal of Computer-Mediated Communication, 13,1, 210-230 
Brown, A. (1994) Groupwork. 3rd edition. Aldershot: Ashgate

Chaudhary, S., Avis, M. and Munn-Giddings, C. (2010) The lifespan and lifecycle of self help groups: A retrospective study of groups in Nottingham, UK. Health and Social Care in the Community, 18, 4, 346-354

Correa, T., Hinsley, A.W. and Zuniga, H.G. (2010) Who interacts on the web? : The intersection of users' personality and social media use. Computer in Human Behaviour, 26, 247-253

Dobransky, K. and Hargittai, E. (2006) The disability divide in internet access and use. Information, Communication and Society, 9, 3, 313-334

Douglas, T. (1993) A Theory of Groupwork Practice. London: Macmillan

Elsdon, K., Reynolds, J. and Stewart, S. (2000) Sharing Experience, Living and Learning: A Study of Self Help Groups. London: Community Matters

ESTEEM (2013) Effective support for self- help/mutual aid groups (ESTEEM): Stage 2 Final Report. [Accessed 6 April 2013 at: http://www.selfhelp.org. uk/research]

Finn, J. (1999) An exploration of helping process in an online self-help group focusing on issues of disability. Health and Social Work, 24, 3, 220-231

Fisher, J. (2012) Who gives a tweet: Assessing patients' interest in the use of social media for health care. Worldviews in Evidence Based Nursing, 2, 100-108

Gray, R., Fitch, M., Davis, C. and Phillips, C. (1997) A qualitative study of breast cancer self help groups. Psycho-Oncology, 6, $279-289$

Grieve, R., Indian, M., Witteveen, K., Tolan, G.A. and Marrington, J. (2013) Face-to-Face or Facebook: Can social connectedness be derived online? Computers in Human Behaviour, 29, 604-609

Helsper, E.J. (2011) The emergence of a digital underclass. Digital policies in the UK and evidence for inclusion. Media Policy brief 3, Digital Inclusion Dossier. LSE Media Policy Project, July. [Accessed 13 March 2013 at http://blogs.lse.ac.uk/ mediapolicyproject/2011/07/26/digital-underclass-emerges-in-the-uk/]

King, S.A. and Moreggi, D. (2006) Internet self-help and support groups: The pros and cons of text-based mutual aid. in J. Gackenback (Ed.) Psychology and the Internet: Intrapersonal, interpersonal and transpersonal implications. (2nd ed.). London: Elsevier. (pp. 221-244)

Levine, J. (2005) An exploration of female social work students' participation in online and face-to-face self-help groups. Groupwork, 15, 2, 61-79

Madara, E. J. (1997) The mutual-aid self-help online revolution. Social Policy, $27,3,20-26$

Madden, S. (2011) The parent to parent group. Groupwork, 21, 2, 35-49 Munn-Giddings, C. and Borkman, T. (2005) Self-help/mutual aid as a 
psychosocial phenomenon. in S. Ramon and J.E. Williams (Eds.) Mental Health at the Crossroads: The promise of the psychosocial approach. Aldershot: Ashgate (pp137-155)

Munn-Giddings, C. and McVicar, A. (2006) Self-help groups as mutual support:

What do carers value? Health and Social Care in the Community, 15, 1, 26-34 Murthy, D. (2012) Towards a sociological understanding of social media:

Theorizing Twitter. Sociology, 46, 6, 1059-1073

Pistrang, N., Barker, C. and Humphreys, K. (2008) Mutual Help Groups for Mental Health Problems: A Review of Effectiveness Studies. American Journal of Community Psychology, 42, 110 - 121

Seebohm, P., Chaudhary, S., Boyce, M., Elkan, R., Avis, M. and Munn-Giddings, C. (2013) The contribution of self-help/mutual aid groups to mental wellbeing. Health and Social Care in the Community, 21, 4, 3910401, DOI: 10.1111/ hsc. 12021

Seil, D. (2012) Harness social media, enhance your practice. Social Media, July, $40-46$

Selwyn, N. (2004) Reconsider political and popular understandings of the digital divide. New Media and Society, 6, 3, 341-362

Shepherd, M.D., Schoenberg, M., Slavich, S., Wituk, S., Warren, M. and Meissen, G. (1999) Continuum of professional involvement in self-help groups. Journal of Community Psychology, 27, 1, 39-53

Simon, S.R. and Stauber, K.W. (2011) Technology and groupwork: A mandate and an opportunity. Groupwork, 21, 3, 7-21

Sourbati, M. (2009) 'It could be useful, but not for me at the moment': Older people, internet access and e-public service provision. New Media and Society, $11,7,1083-1100$

Sourbati, M. (2012) Disabling communications? A capabilities perspective on media access, social inclusion and communication policy. Media Culture and Society, 34, 5, 571-587

Wilson J. (1994) Two Worlds: Self Help Groups and Professionals. London: Venture Press

Winter, R. and Munn-Giddings, C. (2001) A handbook for action researchers in health and social care. London: Routledge

Wituk, S., Shepherd, M., Warren, M. and Meissen, G. (2002) Factors Contributing to the Survival of Self Help Groups. American Journal of Community Psychology, 30, 3, 349-366 